\title{
Immunogenicity noninferiority study of 2 doses and 3 doses of an Escherichia coli-produced HPV bivalent vaccine in girls vs. 3 doses in young women
}

\author{
Yue-Mei $\mathrm{Hu}^{1 \dagger}$, Meng Guo ${ }^{2 \dagger}$, Chang-Gui $\mathrm{Li}^{3 \dagger}$, Kai Chu ${ }^{1}$, Wen-Gang $\mathrm{He}^{2}$, Jing Zhang ${ }^{4}$, \\ Jian-Xiang $\mathrm{Gu}^{4}$, Juan $\mathrm{Li}^{3}$, Hui Zhao ${ }^{3}$, Xiang-Hong $\mathrm{Wu}^{4}$, Bi-Zhen Lin ${ }^{5}$, Zhi-Jie Lin ${ }^{5}$, \\ Xing-Mei $\mathrm{Yao}^{2}$, Ya-Fei $\mathrm{Li}^{2}$, Fei-Xue Wei ${ }^{2}$, Yue Huang ${ }^{2}$, Ying-Ying Su${ }^{2}$, Feng-Cai Zhu ${ }^{1}$, \\ Shou-Jie Huang ${ }^{2}$, Hui-Rong Pan ${ }^{5}$, Ting $\mathrm{Wu}^{2}$, Jun Zhang $^{2 *} \&$ Ning-Shao Xia ${ }^{2 *}$ \\ ${ }^{1}$ Jiangsu Provincial Center for Disease Control and Prevention, Nanjing 210009, China; \\ ${ }^{2}$ The State Key Laboratory of Molecular Vaccinology and Molecular Diagnostics, National Institute of Diagnostics and Vaccine Development \\ in Infectious Diseases, Collaborative Innovation Center of Biologic Products, School of Public Health, Xiamen University, \\ Xiamen 361102, China; \\ ${ }^{3}$ National Institute for Food and Drug Control, Beijing 102629, China; \\ ${ }^{4}$ Sheyang Center for Disease Control and Prevention, Sheyang 244300, China; \\ ${ }^{5}$ Xiamen Innovax Biotech Company, Xiamen 361022, China
}

Received March 12, 2019; accepted April 16, 2019; published online June 21, 2019

\begin{abstract}
A new HPV-16/18 bivalent vaccine expressed by the Escherichia coli has been proven to be efficacious in adult women. A randomized, immunogenicity noninferiority study of this candidate vaccine was conducted in December 2015 in China. Girls aged 9-14 years were randomized to receive 2 doses at months 0 and $6(n=301)$ or 3 doses at months 0,1 and $6(n=304)$. Girls aged $15-17$ years $(n=149)$ and women aged 18-26 years $(n=225)$ received 3 doses. The objectives included noninferiority analysis of the $\mathrm{IgG}$ geometric mean concentration (GMC) ratio $(95 \% \mathrm{CI}$, lower bound $>0.5)$ to HPV-16 and HPV-18 at month 7 in girls compared with women. In the per-protocol set, the GMC ratio of IgG was noninferior for girls aged 9-17 years receiving 3 doses compared with women $(1.76$ (95\% CI, 1.56, 1.99) for HPV-16 and 1.93 (95\% CI, 1.69, 2.21) for HPV-18) and noninferior for girls aged 9-14 years receiving 2 doses compared with women $(1.45$ (95\% CI, 1.25, 1.62) for HPV-16 and 1.17 (95\% CI, $1.02,1.33)$ for HPV-18). Noninferiority was also demonstrated for neutralizing antibodies. The immunogenicity of the HPV vaccine in girls receiving 3 or 2 doses was noninferior compared with that in young adult women.
\end{abstract}

immunobridging, noninferiority, human papillomavirus, vaccine, Escherichia coli, girls

Citation: Hu, Y.M., Guo, M., Li, C.G., Chu, K., He, W.G., Zhang, J., Gu, J.X., Li, J., Zhao, H., Wu, X.H., et al. (2020). Immunogenicity noninferiority study of 2 doses and 3 doses of an Escherichia coli-produced HPV bivalent vaccine in girls vs. 3 doses in young women. Sci China Life Sci 63, 582-591. https://doi.org/10.1007/s11427-019-9547-7

\section{INTRODUCTION}

Human papillomavirus (HPV) infection contributes to al-

†Contributed equally to this work

*Corresponding authors (NingShao Xia, email: nsxia@xmu.edu.cn; Jun Zhang, email:

zhangj@xmu.edu.cn) most all cervical cancers and a substantial fraction of other anogenital and oropharyngeal cancers in women (de Martel et al., 2017). Cervical cancer is the 2 nd most common female cancer in the women aged 15 to 44 years in the world (Bruni et al., 2019). It is estimated that every years, 569,847 women are diagnosed with cervical cancer, and 311,365 die from the 
disease (Bruni et al., 2019), among which 70.8\% are attributed to HPV-16 and/or HPV-18 infection (de Martel et al., 2017). In 2015, the number of cervical cancer cases in China was approximately 98.9 thousand, with 30.5 thousand related deaths (Chen et al., 2016).

Until now, three HPV vaccines have been licensed, including a bivalent vaccine (HPV-16 and HPV-18), a quadrivalent vaccine (HPV-6, HPV-11, HPV-16 and HPV-18) and a 9-valent vaccine (HPV-6, HPV-11, HPV-16, HPV-18, HPV-31, HPV-33, HPV-45, HPV-52 and HPV-58), all of which are safe and highly efficacious against vaccine typerelated anogenital cancers and high-grade precancer lesions in adult women (Harper et al., 2004; Joura et al., 2015; World Health Organization, 2017). Due to ethical constraints on gynecological examinations, it is difficult to conduct efficacy studies in adolescent and preadolescent girls, who are usually before their sexual debut, although all 3 vaccines are approved to be used in girls based on immunobridging noninferiority data (European Medicines Agency, Cervarix; European Medicines Agency, Gardasil 9; European Medicines Agency, Gardasil), and all are included in national immunization programs worldwide. In 2014, the World Health Organization (WHO) changed its recommendation from a 3-dose schedule to a 2-dose schedule for girls aged 9-14 years old (World Health Organization, 2014).

Although HPV vaccines are powerful tools for controlling HPV-related cancer, the limited production capacity and high cost of currently available HPV vaccines have impeded their wider use, especially in low-resource countries where the related disease burden is even higher. Recently, an Escherichia coli-based recombinant HPV-16 and HPV-18 bivalent vaccine (Xiamen Innovax Biotech, Xiamen, China) was successfully developed, and the vaccine is well tolerated $(\mathrm{Hu}$ et al., 2014; Qiao et al., 2019; Wu et al., 2015), with a high efficacy against high-grade genital lesions (Qiao et al., 2019) related to HPV-16 and HPV-18 in women aged 18-45 years.

In this study, we assessed whether the immunogenicity of the HPV vaccine given on a 2-dose or 3-dose schedule in girls is noninferior to that in adult women receiving 3 doses.

\section{RESULTS}

\section{Baseline characteristics}

A total of 979 participants were enrolled, including 605 girls aged 9-14 years, 149 girls aged 15-17 years and 225 women aged 18-26 years. Girls and women aged 15 and above were allocated to receive 3 doses at months 0,1 and 6. Almost all girls aged 9-14 years were randomized to receive 2 doses at months 0 and 6 or to receive 3 doses at months 0,1 and 6 . Only one girl in this age group missed randomization by mistake and received 3 doses (Figure 1). A total of $97.2 \%$ $(952 / 979)$ of the participants received the scheduled vaccine doses, and 95.3\% (933/979) were evaluable for the perprotocol analysis (Figure 1). The most frequent reasons for exclusion from the primary analysis were not receiving the whole vaccination course and missing serology data at 7 mo. The basic characteristics of the participants at enrollment are presented in Table 1. Age was balanced between the 2-dose and 3-dose groups in girls aged 9-14 years. For IgG antibody, $12.6 \%(95 / 753)$ and $8.5 \%(64 / 753)$ of girls aged 9-17 were seropositive for HPV-16 and HPV-18 at entry, respectively, while $20.4 \%$ and $13.8 \%$ were seropositive in women aged $18-26$ years. For neutralizing antibodies, $0.4 \%(3 / 753)$ and $0.9 \%$ (7/753) of girls aged 9-17 were positive for HPV16 and HPV-18, respectively, and the ratios were $8.9 \%$ and $4.9 \%$ in the women.

\section{Immunogenicity}

In the per-protocol cohort, all the study participants except 1 woman aged 24 year seroconverted for both IgG and neutralizing antibodies of HPV-16 and HPV-18 at one month after the final dose (month 7). The women did not seroconvert for HPV-18 neutralizing antibody. The seroconversion rates at $7 \mathrm{mo}$. in girls receiving 2 doses or 3 doses were noninferior to those in women receiving 3 doses (Table 2). The results in the intention-to-treat analysis were consistent with the per-protocol analysis (Table S1 in Supporting Information). At month 6, only IgG antibodies were measured, and all participants receiving 3 doses seroconverted, except for 1 girl aged 17 years who did not seroconvert for HPV-18 IgG. The seroconversion rate at month 6 in girls receiving 3 doses was noninferior to that in women receiving 3 doses (Table 2). For the 2-dose group, $100 \%(267 / 267)$ and $98.6 \%(271 / 275)$ of the girls aged 9-14 years seroconverted for IgG to HPV-16 and HPV-18 at month 6 , respectively (Table 2 ).

For the per-protocol analysis, at month 7 , in girls aged 9-14 years receiving 2 doses, girls aged 9-14 years receiving 3 doses, girls aged 9-17 years receiving 3 doses and women aged 18-26 years receiving 3 doses, the geometric mean concentration (GMC) of IgG antibodies to HPV-16 was 2219 IU mL $\mathrm{mL}^{-1}$ (95\% CI, 2045, 2406), $3163 \mathrm{IU} \mathrm{mL}^{-1}$ (95\% CI, 2914, 3432), $2749 \mathrm{IU} \mathrm{mL}^{-1}$ (95\% CI, 2569, 2914), and 1560 IU mL $\mathrm{mL}^{-1}(95 \% \mathrm{CI}, 1405,1731)$, respectively, and the GMC of IgG antibodies to HPV-18 was $397 \mathrm{IU} \mathrm{mL}^{-1}$ (95\% CI, 365, 431), $798 \mathrm{IU} \mathrm{mL}^{-1}$ (95\% CI, 730, 873), $656 \mathrm{IU} \mathrm{mL}^{-1}(95 \%$ $\mathrm{CI}, 608,709)$, and $340 \mathrm{IU} \mathrm{mL}^{-1}(95 \% \mathrm{CI}, 306,378)$, respectively. The GMC level in girls was noninferior to that in women receiving 3 doses, with GMC ratios of 1.42 (95\% CI, 1.25, 1.62), 2.03 (95\% CI, 1.78, 2.31), and 1.76 (95\% CI, $1.56,1.99)$ for HPV-16 and 1.17 (95\% CI, 1.02, 1.33), 2.35 (95\% CI, 2.04, 2.70), and 1.93 (95\% CI, 1.69, 2.21) for HPV18 (Table 3 ). Immunogenicity of the vaccine in the subgroup of girls aged 15-17 years receiving 3 doses also reached 


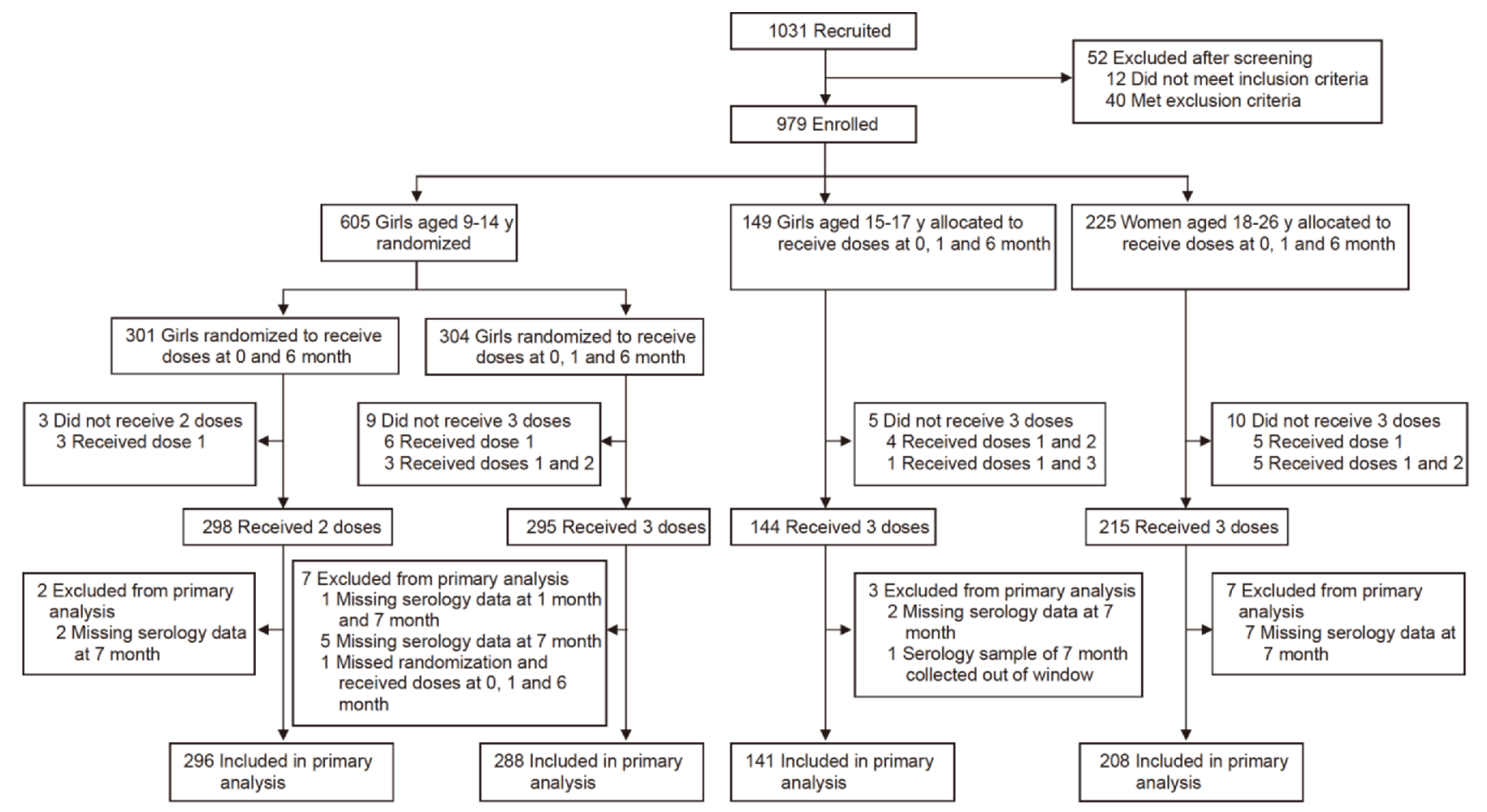

Figure 1 Flowchart of the study.

Table 1 Characteristics of participants at enrollment

\begin{tabular}{|c|c|c|c|c|}
\hline & $\begin{array}{l}\text { Women aged } 18-26 \text { year } \\
\quad(3 \text { doses })(n=225)\end{array}$ & $\begin{array}{l}\text { Girls aged } 9-14 \text { year } \\
(2 \text { doses })(n=301)\end{array}$ & $\begin{array}{l}\text { Girls aged } 9-14 \text { year } \\
(3 \text { doses })(n=304)\end{array}$ & $\begin{array}{l}\text { Girls aged } 9-17 \text { year } \\
(3 \text { doses })(n=453)\end{array}$ \\
\hline Age, mean (SD) (year) & $22.4(2.6)$ & $11.5(1.8)$ & $11.4(1.8)$ & $12.9(2.5)$ \\
\hline \multicolumn{5}{|l|}{ Age group, $n$ (ratio) } \\
\hline 9-11 year & 0 & $151(50.2 \%)$ & $155(51.0 \%)$ & $155(34.2 \%)$ \\
\hline $12-14$ year & 0 & $150(49.8 \%)$ & $149(49.0 \%)$ & $149(32.9 \%)$ \\
\hline $15-17$ year & 0 & 0 & 0 & $149(32.9 \%)$ \\
\hline $18-26$ year & $225(100.0 \%)$ & 0 & 0 & 0 \\
\hline \multicolumn{5}{|l|}{ Seropositive IgG antibody } \\
\hline HPV-16, No./total No. (\%) & $46 / 225(20.4)$ & 29/301 (9.6) & $43 / 303(14.2)^{\mathrm{a})}$ & $66 / 452(14.6)^{\mathrm{a})}$ \\
\hline GMC $\left(\mathrm{IU} \mathrm{mL}^{-1}\right)^{\mathrm{b})}$ & 9.2 & 5.5 & 6.2 & 6.5 \\
\hline HPV-18, No./total No. (\%) & $31 / 225(13.8)$ & $21 / 301(7.0)$ & $27 / 303(8.9)^{\mathrm{a})}$ & $43 / 452(9.5)^{\mathrm{a})}$ \\
\hline GMC $\left(\mathrm{IU} \mathrm{mL}{ }^{-1}\right)^{\mathrm{b})}$ & 4.3 & 5.2 & 4.9 & 5.2 \\
\hline \multicolumn{5}{|l|}{ Seropositive neutralizing antibody } \\
\hline HPV-16, No./total No. (\%) & 20/225 (8.9) & $3 / 301(1.0)$ & $0 / 303(0.0)^{\mathrm{a})}$ & $0 / 452(0.0)^{a)}$ \\
\hline GMC $\left(\mathrm{IU} \mathrm{mL}^{-1}\right)^{\mathrm{b})}$ & 8.6 & 3.9 & - & - \\
\hline HPV-18, No./total No. (\%) & $11 / 225(4.9)$ & 3/301 (1.0) & $3 / 303(1.0))^{a)}$ & $4 / 452(0.9)^{a)}$ \\
\hline GMC $\left(\mathrm{IU} \mathrm{mL}{ }^{-1}\right)^{\mathrm{b})}$ & 5.0 & 2.3 & 2.5 & 3.1 \\
\hline
\end{tabular}

a) One girl aged 9 year did not have blood taken at month 0 ; b) only seropositive sample were calculated. Abbreviations: 3 doses, vaccinated at 0,1 and 6 months; 2 doses, vaccinated at 0 , and 6 months; SD, standard deviation; HPV, human papillomavirus; No., number; GMC, geometric mean concentration; IU, international unit.

noninferiority (Table S2 in Supporting Information). The results of the neutralizing antibodies were similar to those of the IgG antibodies. Reverse cumulative distribution curves of IgG and neutralizing antibodies at month 7 are shown in Figure S1 in Supporting Information. For both $\operatorname{IgG}$ and neutralizing antibodies to HPV-16 or HPV-18, the antibody levels at month 7 decreased as age increased (Figure 2). At month 6, the GMC levels of IgG antibodies in girls receiving 3 doses were also noninferior to those in women receiving 3 doses for both HPV-16 and HPV-18 (Table 3). The results in the intention-to-treat analysis were consistent with the perprotocol analysis and reached noninferiority (Table S3 in 
Table 2 Noninferiority analysis of seroconversion rate in the PPS cohort

\begin{tabular}{|c|c|c|c|c|c|c|c|c|c|c|}
\hline \multicolumn{2}{|c|}{$\begin{array}{l}\text { Women aged } 18-26 \text { year } \\
(3 \text { doses })\left(n=208^{\text {a) }}\right)\end{array}$} & \multicolumn{2}{|c|}{$\begin{array}{l}\text { Girls aged } 9-14 \text { year } \\
(2 \text { doses })\left(n=296^{\text {a) }}\right)\end{array}$} & \multicolumn{2}{|c|}{$\begin{array}{l}\text { Girls aged } 9-14 \text { year } \\
(3 \text { doses })\left(n=288^{\text {a) }}\right)\end{array}$} & \multicolumn{2}{|c|}{$\begin{array}{l}\text { Girls aged } 9-17 \text { year } \\
(3 \text { doses })\left(n=429^{\mathrm{a})}\right)\end{array}$} & \multicolumn{3}{|c|}{$\begin{array}{l}\text { Difference in seroconversion rates }(95 \% \mathrm{CI} \\
\text { vs. women aged } 18-26 \text { year ( } 3 \text { doses) }\end{array}$} \\
\hline $\begin{array}{l}\text { No./ Total } \\
\text { No. }\end{array}$ & $\begin{array}{l}\text { Seroconver- } \\
\text { sion }(\%) \\
(95 \% \mathrm{CI})\end{array}$ & $\begin{array}{l}\text { No./ Total } \\
\text { No. }\end{array}$ & $\begin{array}{c}\text { Seroconver- } \\
\text { sion }(\%) \\
(95 \% \text { CI })\end{array}$ & $\begin{array}{l}\text { No./ Total } \\
\text { No. }\end{array}$ & $\begin{array}{l}\text { Seroconver- } \\
\text { sion }(\%)(95 \% \\
\text { CI) }\end{array}$ & $\begin{array}{l}\text { No./ Total } \\
\text { No. }\end{array}$ & $\begin{array}{c}\text { Seroconver- } \\
\text { sion }(\%) \\
(95 \% \mathrm{CI})\end{array}$ & $\begin{array}{c}\text { Girls aged } \\
\text { 9-14 year ( } 2 \\
\text { doses) }\end{array}$ & $\begin{array}{c}\text { Girls aged } \\
9-14 \text { year ( } 3 \\
\text { doses) }\end{array}$ & $\begin{array}{c}\text { Girls aged } \\
9-17 \text { year }(3 \\
\text { doses })\end{array}$ \\
\hline
\end{tabular}

At one month after the final dose (At month 7)

IgG antibody ${ }^{\text {) }}$

\begin{tabular}{|c|c|c|c|c|c|c|c|c|c|c|c|}
\hline HPV-16 & $165 / 165$ & $\begin{array}{c}100.0 \\
(97.8,100.0)\end{array}$ & $267 / 267$ & $\begin{array}{c}100.0 \\
(98.6,100.0)\end{array}$ & $246 / 246$ & $\begin{array}{c}100.0 \\
(98.5,100.0)\end{array}$ & $366 / 366$ & $\begin{array}{c}100.0 \\
(99.0,100.0)\end{array}$ & $\begin{array}{c}0.00 \\
(-1.42,2.28)\end{array}$ & $\begin{array}{c}0.00 \\
(-1.54,2.28)\end{array}$ & $\begin{array}{c}0.00 \\
(-1.04,2.28)\end{array}$ \\
\hline HPV-18 & $178 / 178$ & $\begin{array}{c}100.0 \\
(97.9,100.0)\end{array}$ & $275 / 275$ & $\begin{array}{c}100.0 \\
(98.7,100.0)\end{array}$ & $262 / 262$ & $\begin{array}{c}100.0 \\
(98.6,100.0)\end{array}$ & $389 / 389$ & $\begin{array}{c}100.0 \\
(99.1,100.0)\end{array}$ & $\begin{array}{c}0.00 \\
(-1.38,2.11)\end{array}$ & $\begin{array}{c}0.00 \\
(-1.45,2.11)\end{array}$ & $\begin{array}{c}0.00 \\
(-0.98,2.11)\end{array}$ \\
\hline \multicolumn{12}{|c|}{ Neutralizing antibody ${ }^{\text {b) }}$} \\
\hline HPV-16 & $189 / 189$ & $\begin{array}{c}100.0 \\
(98.1,100.0)\end{array}$ & $293 / 293$ & $\begin{array}{c}100.0 \\
(98.7,100.0)\end{array}$ & $288 / 288$ & $\begin{array}{c}100.0 \\
(98.7,100.0)\end{array}$ & $429 / 429$ & $\begin{array}{c}100.0 \\
(99.1,100.0)\end{array}$ & $\begin{array}{c}0.00 \\
(-1.29,1.99)\end{array}$ & $\begin{array}{c}0.00 \\
(-1.32,1.99)\end{array}$ & $\begin{array}{c}0.00 \\
(-0.89,1.99)\end{array}$ \\
\hline HPV-18 & 197/198 & $\begin{array}{c}99.5 \\
(97.2,100.0)\end{array}$ & $293 / 293$ & $\begin{array}{c}100.0 \\
(98.7,100.0)\end{array}$ & $285 / 285$ & $\begin{array}{c}100.0 \\
(98.7,100.0)\end{array}$ & $425 / 425$ & $\begin{array}{c}100.0 \\
(99.1,100.0)\end{array}$ & $\begin{array}{c}0.51 \\
(-0.80,2.81)\end{array}$ & $\begin{array}{c}0.51 \\
(-0.83,2.81)\end{array}$ & $\begin{array}{c}0.51 \\
(-0.40,2.81)\end{array}$ \\
\hline
\end{tabular}

At six months after the first dose (At month 6)

IgG antibody ${ }^{c)}$

\begin{tabular}{|c|c|c|c|c|c|c|c|c|c|c|c|}
\hline HPV-16 & $165 / 165$ & $\begin{array}{c}100.0 \\
(97.8,100.0)\end{array}$ & $267 / 267$ & $\begin{array}{c}100.0 \\
(98.6,100.0)\end{array}$ & $246 / 246$ & $\begin{array}{c}100.0 \\
(98.5,100.0)\end{array}$ & $366 / 366$ & $\begin{array}{c}100.0 \\
(99.0,100.0)\end{array}$ & - & $\begin{array}{c}0.00 \\
(-1.54,2.28)\end{array}$ & $\begin{array}{c}0.00 \\
(-1.04,2.28)\end{array}$ \\
\hline HPV-18 & $178 / 178$ & $\begin{array}{c}100.0 \\
(97.9,100.0)\end{array}$ & $271 / 275$ & $\begin{array}{c}98.5 \\
(96.3,99.6)\end{array}$ & $262 / 262$ & $\begin{array}{c}100.0 \\
(98.6,100.0)\end{array}$ & $388 / 389$ & $\begin{array}{c}99.7 \\
(98.6,100.0)\end{array}$ & - & $\begin{array}{c}0.00 \\
(-1.45,2.11)\end{array}$ & $\begin{array}{c}-0.26 \\
(-1.44,1.86)\end{array}$ \\
\hline
\end{tabular}

a) The number included those in the respective age groups who received all the scheduled vaccine doses, had effective antibody results at day 0 and month 7, and had no important protocol violation. b) The denominators in the table included those in the respective age groups who received all the scheduled vaccine doses, had effective antibody results at day 0 and month 7 , had no important protocol violation, and were antibody (the same antibody index and same HPV type)-seronegative at entry. c) The denominators in the table included those in the respective age groups who received all the scheduled vaccine doses, had effective antibody results at day 0 , month 6 and month 7, had no important protocol violation, and were antibody (the same antibody index and same HPV type)-seronegative at entry. Abbreviations: PPS, per-protocol set; 3 doses, vaccinated at 0, 1 and 6 months; 2 doses, vaccinated at 0, and 6 months; CI, confidence interval; No., number; HPV, human papillomavirus.

Table 3 Noninferiority analysis of geometric mean concentrations (GMCs) in the PPS cohort

\begin{tabular}{|c|c|c|c|c|c|c|c|c|c|c|}
\hline \multicolumn{2}{|c|}{$\begin{array}{l}\text { Women aged } 18-26 \text { year } \\
(3 \text { doses })\left(n=208^{\text {a) }}\right)\end{array}$} & \multicolumn{2}{|c|}{$\begin{array}{l}\text { Girls aged } 9-14 \text { year } \\
(2 \text { doses })\left(n=296^{\text {a) }}\right)\end{array}$} & \multicolumn{2}{|c|}{$\begin{array}{l}\text { Girls aged } 9-14 \text { year } \\
(3 \text { doses })\left(n=288^{\mathrm{a})}\right)\end{array}$} & \multicolumn{2}{|c|}{$\begin{array}{l}\text { Girls aged } 9-17 \text { year } \\
(3 \text { doses })\left(n=429^{\text {a) }}\right)\end{array}$} & \multicolumn{3}{|c|}{$\begin{array}{c}\text { Ratio of GMC }(95 \% \mathrm{CI}) \text { vs. Women } \\
\text { aged } 18-26 \text { year ( } 3 \text { doses })\end{array}$} \\
\hline No. & $\begin{array}{l}\text { GMC }(95 \% \\
\text { CI) }\left(\mathrm{IU} \mathrm{mL}^{-1}\right)\end{array}$ & No. & $\begin{array}{l}\text { GMC }(95 \% \\
\mathrm{CI})\left(\mathrm{IU} \mathrm{mL} \mathrm{mL}^{-1}\right)\end{array}$ & No. & $\begin{array}{l}\text { GMC }(95 \% \\
\text { CI) }\left(\mathrm{IU} \mathrm{mL}^{-1}\right)\end{array}$ & No. & $\begin{array}{l}\text { GMC }(95 \% \\
\text { CI) }\left(\mathrm{IU} \mathrm{mL}^{-1}\right)\end{array}$ & $\begin{array}{l}\text { Girls aged } \\
9-14 \text { year } \\
(2 \text { doses })\end{array}$ & $\begin{array}{l}\text { Girls Aged } \\
9-14 \text { year } \\
\text { (3 doses) }\end{array}$ & $\begin{array}{c}\text { Girls aged } \\
9-17 \text { year } \\
\text { (3 doses) }\end{array}$ \\
\hline
\end{tabular}

At one month after the final dose (At month 7)

IgG antibody ${ }^{\text {b) }}$

\begin{tabular}{|c|c|c|c|c|c|c|c|c|c|c|c|}
\hline HPV-16 & 165 & $\begin{array}{c}1560 \\
(1405,1731)\end{array}$ & 267 & $\begin{array}{c}2219 \\
(2045,2406)\end{array}$ & 246 & $\begin{array}{c}3163 \\
(2914,3432)\end{array}$ & 366 & $\begin{array}{c}2749 \\
(2569,2941)\end{array}$ & $\begin{array}{c}1.42 \\
(1.25,1.62)\end{array}$ & $\begin{array}{c}2.03 \\
(1.78,2.31)\end{array}$ & $\begin{array}{c}1.76 \\
(1.56,1.99)\end{array}$ \\
\hline HPV-18 & 178 & $\begin{array}{c}340 \\
(306,378)\end{array}$ & 275 & $\begin{array}{c}397 \\
(365,431)\end{array}$ & 262 & $\begin{array}{c}798 \\
(730,873)\end{array}$ & 389 & $\begin{array}{c}656 \\
(608,709)\end{array}$ & $\begin{array}{c}1.17 \\
(1.02,1.33)\end{array}$ & $\begin{array}{c}2.35 \\
(2.04,2.70)\end{array}$ & $\begin{array}{c}1.93 \\
(1.69,2.21)\end{array}$ \\
\hline \multicolumn{12}{|c|}{ Neutralizing antibody ${ }^{\text {b) }}$} \\
\hline HPV-16 & 189 & $\begin{array}{c}1012 \\
(900,1136)\end{array}$ & 293 & $\begin{array}{c}1466 \\
(1339,1606)\end{array}$ & 288 & $\begin{array}{c}2154 \\
(1976,2347)\end{array}$ & 429 & $\begin{array}{c}1903 \\
(1774,2042)\end{array}$ & $\begin{array}{c}1.45 \\
(1.25,1.68)\end{array}$ & $\begin{array}{c}2.13 \\
(1.85,2.45)\end{array}$ & $\begin{array}{c}1.88 \\
(1.65,2.14)\end{array}$ \\
\hline HPV-18 & 198 & $\begin{array}{c}503 \\
(443,571)\end{array}$ & 293 & $\begin{array}{c}607 \\
(555,663)\end{array}$ & 285 & $\begin{array}{c}1323 \\
(1204,1453)\end{array}$ & 425 & $\begin{array}{c}1099 \\
(1015,1192)\end{array}$ & $\begin{array}{c}1.21 \\
(1.04,1.40)\end{array}$ & $\begin{array}{c}2.63 \\
(2.25,3.07)\end{array}$ & $\begin{array}{c}2.19 \\
(1.89,2.53)\end{array}$ \\
\hline
\end{tabular}

IgG antibody $^{\text {c) }}$

\begin{tabular}{|c|c|c|c|c|c|c|c|c|c|c|c|}
\hline HPV-16 & 165 & $\begin{array}{c}251 \\
(227,277)\end{array}$ & 267 & $81(74,88)$ & 246 & $\begin{array}{c}446 \\
(416,478)\end{array}$ & 366 & $\begin{array}{c}402 \\
(378,428)\end{array}$ & - & $\begin{array}{c}1.78 \\
(1.57,2.01)\end{array}$ & $\begin{array}{c}1.60 \\
(1.43,1.80)\end{array}$ \\
\hline HPV-18 & 178 & $42(38,47)$ & 275 & $16(14,17)$ & 262 & $79(73,86)$ & 389 & $69(64,74)$ & - & $\begin{array}{c}1.88 \\
(1.66,2.13)\end{array}$ & $\begin{array}{c}1.63 \\
(1.45,1.84)\end{array}$ \\
\hline
\end{tabular}

a) The number included those in the respective age groups who received all the scheduled vaccine doses, had effective antibody results at day 0 and month 7, and had no important protocol violation. b) The denominators in the table included those in the respective age groups who received all the scheduled vaccine doses, had effective antibody results at day 0 and month 7 , had no important protocol violation, and were antibody (the same antibody index and same HPV type)-seronegative at entry. c) The denominators in the table included those in the respective age groups who received all the scheduled vaccine doses, had effective antibody results at day 0 , month 6 and month 7 , had no important protocol violation, and were antibody (the same antibody index and same HPV type)-seronegative at entry. Abbreviations: PPS, per-protocol set; 3 doses, vaccinated at 0,1 and 6 months; 2 doses, vaccinated at 0 , and 6 months; No., number; IU, international unit; HPV, human papillomavirus. 

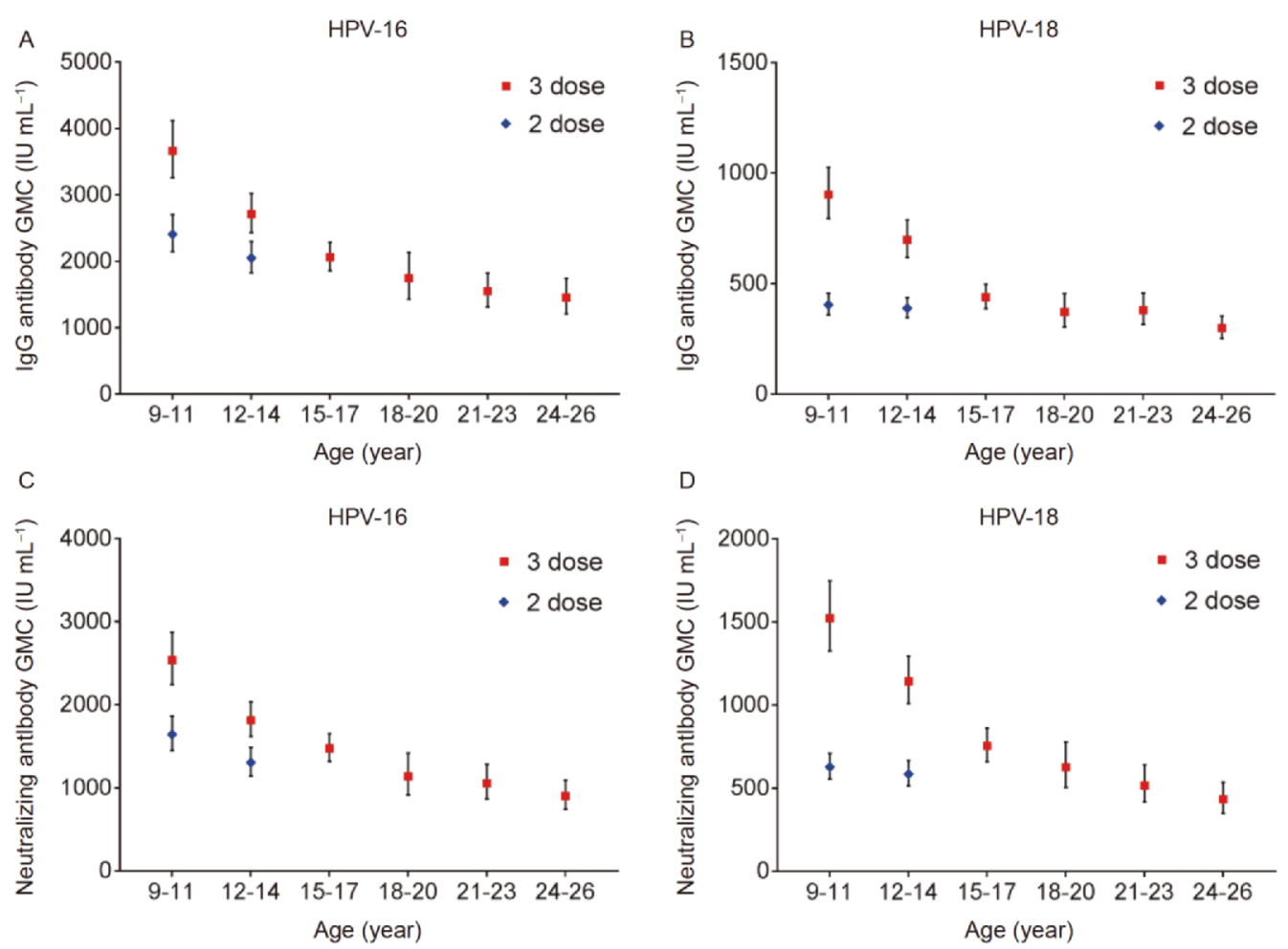

Figure 2 (Color online) Geometric mean concentrations (GMCs) in each 3-year age group of the participants who received 2 doses or 3 doses (per-protocol cohort). At month 7 (one month after the final dose), GMCs of IgG level (A, B) and neutralizing antibody level (C, D) to HPV-16 (A, C) and HPV-18 (B, D) in each 3-year age group of the per-protocol cohorts of those who received 3 doses (red square) or 2 doses (blue diamond) were shown. I bars represent $95 \%$ confidence intervals. The bars for the 2-dose receivers (blue diamond) were artificially moved slightly to the right to allow better discrimination from the 3dose receivers (red square). At month 7, in the per-protocol cohort, all but 1 woman aged 24 years seroconverted for both IgG and neutralizing antibodies to both HPV-16 and HPV-18. The woman did not seroconvert for HPV-18 neutralizing antibody. The antibody level of the negative sample was artificially set as half of the cutoff value. Abbreviations: HPV, human papillomavirus; 2 doses, vaccinated at 0 , and 6 months; 3 doses, vaccinated at 0,1 and 6 months; IU, international unit.

\section{Supporting Information).}

For girls aged 9-14 years who received 2 doses, the antibody level to HPV-16 was noninferior to that in girls who received 3 doses, with GMC ratios of 0.70 (95\% CI, 0.63 , $0.79)$ for $\mathrm{IgG}$ and $0.68(95 \% \mathrm{CI}, 0.60,0.77)$ for the neutralizing antibody. The GMC noninferiority for HPV-18 was not proven, with ratios of $0.50(95 \% \mathrm{CI}, 0.44,0.56)$ for IgG and $0.46(95 \% \mathrm{CI}, 0.40,0.52)$ for the neutralizing antibody (Table S4 in Supporting Information).

\section{Safety}

A total of 57.6\% (564/979) of the study participants reported adverse reactions, and only $1.2 \%$ (12/979) were judged as grade 3 or more severe. The most frequently reported symptoms, with occurrence rates of more than $10 \%$ in at least one study group, were pain, fever and cough (Table 4), among which all but 2 were mild, at grade 1 or 2 . The rest of the solicited symptoms are listed in Table S5 in Supporting Information. Three participants reported serious adverse events (SAEs) during the study (from day 0 to month 7), and none of them were considered vaccine-related (Table S6 in Supporting Information).

\section{DISCUSSION}

This is the first study on the immunogenicity of a new candidate E. coli-expressed recombinant HPV-16 and HPV-18 bivalent vaccine administered to girls compared with women. Data showed that the vaccine was noninferior in girls aged 15-17 years receiving 3 doses and girls aged 9-14 years receiving 2 doses compared with in women aged 18-26 years receiving 3 doses. Regardless of the vaccine schedule, antibody titers were higher in girls than in women. Safety data of the candidate vaccine in the participants were reassuring.

Due to very few breakthrough cases, immunological correlates of protection have not been established for HPV vaccines in previous large efficacy trials (Joura et al., 2008; Stanley et al., 2006). All three commercialized HPV vaccines are licensed for adolescent and preadolescent girls based on immunogenicity bridging studies of type-specific antibody levels in girls compared with women (Block et al., 2006; Pedersen et al., 2007; Van Damme et al., 2015). The noninferiority criterion, i.e., a lower $95 \%$ confidence bound for the GMT ratio greater than 0.5 , is accepted by regulatory authorities worldwide for HPV vaccines and some other 
Table 4 Adverse events reported in 30 days after each dose ${ }^{\text {a) }}$

\begin{tabular}{|c|c|c|c|c|c|}
\hline & $\begin{array}{l}\text { Women aged } 18-26 \text { year } \\
\text { ( } 3 \text { doses) }(n=225)\end{array}$ & $\begin{array}{l}\text { Girls aged } 9-14 \text { year } \\
(2 \text { doses })(n=301)\end{array}$ & $\begin{array}{l}\text { Girls aged } 9-14 \text { year } \\
(3 \text { doses })(n=304)\end{array}$ & $\begin{array}{c}\text { Girls aged } 9-17 \text { year } \\
(3 \text { doses })(n=453)\end{array}$ & $\begin{array}{c}\text { Total } \\
(n=979)\end{array}$ \\
\hline \multicolumn{6}{|c|}{ Subjects with solicited adverse events within 7 days of each dose } \\
\hline Solicited adverse events & $123(54.7)$ & $163(54.2)$ & $190(62.5)$ & $278(61.4)$ & $564(57.6)$ \\
\hline$\geq$ grade 3 & $2(0.9)$ & $3(1.0)$ & $5(1.6)$ & $7(1.5)$ & $12(1.2)$ \\
\hline Local adverse events & $78(34.7)$ & $73(24.3)$ & $86(28.3)$ & $141(31.1)$ & $292(29.8)$ \\
\hline$\geq$ grade 3 & $2(0.9)$ & $2(0.7)$ & $3(1.0)$ & $4(0.9)$ & $8(0.8)$ \\
\hline Pain & $64(28.4)$ & $68(22.6)$ & $71(23.4)$ & $117(25.8)$ & $249(25.4)$ \\
\hline$\geq$ grade 3 & $0(0.0)$ & $0(0.0)$ & $0(0.0)$ & $0(0.0)$ & $0(0)$ \\
\hline Systemic adverse events & $77(34.2)$ & $126(41.9)$ & $146(48.0)$ & $219(48.3)$ & $422(43.1)$ \\
\hline$\geq$ grade 3 & $0(0.0)$ & $1(0.3)$ & $2(0.7)$ & $3(0.7)$ & $4(0.4)$ \\
\hline Fever & $53(23.6)$ & $92(30.6)$ & $117(38.5)$ & $174(38.4)$ & $319(32.6)$ \\
\hline$\geq$ grade 3 & $0(0.0)$ & $1(0.3)$ & $1(0.3)$ & $1(0.2)$ & $2(0.2)$ \\
\hline Cough & $14(6.2)$ & $25(8.3)$ & $37(12.2)$ & $45(9.9)$ & $84(8.6)$ \\
\hline$\geq$ grade 3 & $0(0.0)$ & $0(0.0)$ & $0(0.0)$ & $0(0.0)$ & $0(0)$ \\
\hline \multicolumn{6}{|c|}{ Subjects with unsolicited adverse events within 30 days of each dose } \\
\hline $\begin{array}{l}\text { Unsolicited adverse } \\
\text { events }\end{array}$ & $111(49.3)$ & $110(36.5)$ & $165(54.3)$ & $239(52.8)$ & $460(47.0)$ \\
\hline$\geq$ grade 3 & $1(0.4)$ & $0(0.0)$ & $3(1.0)$ & $3(0.7)$ & $4(0.4)$ \\
\hline
\end{tabular}

a) Abbreviations: 3 doses, vaccinated at 0,1 and 6 months; 2 doses, vaccinated at 0 , and 6 months.

vaccines (Dobson et al., 2013; Jingyee et al., 2009; Iversen et al., 2016), although the clinical meaning of this immunogenicity difference remains unclear.

In the efficacy trial of this E. coli-expressed HPV vaccine, there were no breakthrough CIN2+ cases, and only one persistent infection case occurred in the vaccine recipients who were negative for HPV antibody at baseline and were DNA-naïve for the relative HPV type from day 0 through month 7 , and thus, the protective antibody levels against CIN2+ and persistent infection remain unestablished. Thus, licensure of the new candidate HPV vaccine in girls must also be based on an immunobridging study and the noninferiority criterion. Two antibody indexes, IgG antibody and neutralizing antibody, were measured. For both antibody indexes and for both HPV-16 and HPV-18, the antibody levels in girls aged 9-17 years receiving 3 doses and girls aged 9-14 years receiving 2 doses were higher than and noninferior to those in women receiving 3 doses. The GMT ratios were similar to the three licensed HPV vaccines (Block et al., 2006; Mariani et al., 2016; Pedersen et al., 2007). Additionally, in the 3-dose groups, noninferiority at month 6 was established in girls compared with women, further verifying the data at month 7 .

In exploratory analyses, in girls aged 9-14 years receiving 2 doses compared with receiving 3 doses, the antibody levels were lower, and noninferiority for HPV-16, but not for HPV18, was established (Table S4 in Supporting Information). Previous studies also showed that some HPV types (HPV-16 in the bivalent HPV vaccine, HPV-18 in the quadrivalent vaccine and HPV-45 in the nonavalent vaccine) did not reach noninferiority or were at the lower margin in those receiving 2 doses of vaccines compared with 3 doses (Dobson et al., 2013; Iversen et al., 2016; Romanowski et al., 2011). Based on data from the national registries, the quadrivalent HPV vaccine effectiveness was estimated to be remain above $90 \%$ for at least 10 years (Kjaer et al., 2018), although the antibody titer, especially to HPV-18, has already decreased to only $6.0 \%\left(44.7 \mathrm{mMU} \mathrm{mL}^{-1}\right.$ vs. $\left.741.2 \mathrm{mMU} \mathrm{mL}^{-1}\right)$ of the peak level and is very close to the antibody level induced by natural infection at 60 months after the first vaccination (Olsson et al., 2007). These data suggest that only small amounts of antibodies are needed for protection and that potential cellular immunity might play an even more important role. However, the clinical meaning of the immunogenicity difference between the 2-dose and 3-dose groups cannot be explained due to a lack of clinical outcome data.

Data from an epidemiological survey in China suggested that the median age of sexual debut is approximately 17 years in female (Zhao et al., 2012). If in the future, girls aged 9 to 14 are targeted in the national immunization program, they may not begin to engage in sexual activity for another 3 to 8 years. Thus, immunopersistence data are important for supporting immunization program decision making.

In May, 2018, the World Health Organization (WHO) called for action towards the elimination of cervical cancer (World Health Organization, 2018). While the worldwide 
HPV vaccination rate is suboptimal (Herrero et al., 2015), the high cost and deficits in HPV vaccine supply impede wider coverage of HPV vaccines. The current candidate HPV vaccine contains $E$. coli-expressed L1-only virus-like particles (VLPs) absorbed to aluminum hydroxide adjuvant (Gu et al., 2017). The E. coli system has many advantages, such as robustness, easy scale-up, a short turnaround period and high expression levels, which make the production cost lower than the eukaryotic system from which current licensed HPV vaccines are expressed (Huang et al., 2017).

The safety data were assuring. Like the adverse-event data collected in the efficacy trial (Qiao et al., 2019), most of the reported adverse events in the participating girls and women were mild, and none of the SAEs reported were vaccinerelated. The high efficacy in young women (Qiao et al., 2019) and the immunological noninferiority and high tolerability of this candidate vaccine in girls imply its potential to supply the large Chinese domestic population and other lowincome countries, which is an important scientific advancement in cervical cancer prevention.

Limitations of this study include lack of antibody persistence data, which we are currently collecting, and an assessment of the long-term noninferiority in girls receiving 3 doses or 2 doses compared with women receiving 3 doses is planned. For the 2-dose schedule, the immunization interval between the first and the last dose should be carefully evaluated, as some evidence indicates that longer intervals may lead to a more robust immune response (Dobson et al., 2013).

Another limitation is that cervical HPV infection was not detected in the participating adult women at baseline, and therefore, some HPV-16 or HPV-18 DNA-positive women might not be excluded from the per-protocol analysis. However, only approximately $0.6 \%$ (for HPV-16) and $0.7 \%$ (for HPV-18) of the Chinese adult women were negative for neutralizing antibody while positive for HPV DNA (Liu et al., 2016), and such a small proportion of DNA-positive women had very little impact on the geometric antibody level of the PPS cohort.

In conclusion, the immunogenicity of the $E$. coli-expressed candidate HPV bivalent vaccine in girls aged 9-17 years receiving 3 doses or girls aged 9-14 years receiving 2 doses is noninferior to that in women aged 18-26 years receiving 3 doses.

\section{MATERIALS AND METHODS}

\section{Study design}

This was a single-centered, age-stratified immunobridging study (ClinicalTrials.gov, NCT02562508) conducted in China to evaluate whether the immunogenicity of girls aged 9-17 years receiving 3 doses (at months 0, 1 and 6) or girls aged 9-14 years receiving 2 doses (at months 0 and 6) was noninferior to that in women aged 18-26 years receiving 3 doses (at months 0,1 and 6) of the E. coli-expressed HPV bivalent vaccine. Safety data were carefully collected and assessed. Independent approval was obtained from the Ethics Committee of the Jiangsu Provincial Center for Disease Control and Prevention. For recruitment, village care providers handed out advertising leaflets to families with a female family member aged 9-26 years at home, and those who were interested were invited to the site at the appointed time to participate in the screening. For the participating girls aged 9-17 years, written informed consent was obtained from their legal guardians, along with written informed acceptance from the study participants themselves. All the participating women signed written informed consent.

Healthy girls or women aged 9-26 years were enrolled in Sheyang County, Jiangsu Province, China, from December 5, 2015, through December 13, 2015. The main study exclusion criteria were pregnancy or lactation at either of the vaccination visits and previous receipt of any HPV vaccines. Detailed inclusion and exclusion criteria are listed in Table S7 in Supporting Information.

At entry, girls aged 9-14 years were randomized in agestratified (9-11 years and 12-14 years, with similar sizes for both age strata) blocks of 6 to receive 2 doses or 3 doses (1:1). Girls aged 15-17 years and women aged 18-45 years were allocated to receive 3 doses (Figure 1). Randomization lists were generated by SAS9.4 software.

The candidate bivalent HPV vaccine contained $40 \mu \mathrm{g}$ of HPV-16 and $20 \mu \mathrm{g}$ of HPV-18 recombinant truncated L1 VLP expressed in E. coli absorbed to $208 \mu \mathrm{g}$ of aluminum adjuvant and suspended in $0.5 \mathrm{~mL}$ of buffered saline ( $\mathrm{Gu}$ et al., 2017; Hu et al., 2014; Wu et al., 2015). Participants were intramuscularly vaccinated at day 0 , month 1 (day 28-60) and month 6 (day 150-240) or at day 0 and month 6 (day 150-240).

Participants were observed for $30 \mathrm{~min}$ after each vaccination and were actively followed up by the investigators at day 7 and day 30 after each vaccination. Any adverse reactions or events that occurred within one month after each vaccination were recorded in a diary card by the study participants or their guardians under the guide of the investigators. Serious adverse events that occurred from the first vaccination through one month after the final dose were carefully investigated and recorded.

\section{Antibody detection}

Both the E. coli-expressed HPV L1 VLP-based enzymelinked immunosorbent assay (ELISA) and the pseudovirionbased neutralization assay (PBNA) were conducted to measure antibody responses. All the serum samples, including those collected at day 0 , month 6 (at the final vaccine 
visit, while before the final vaccination) and month 7 (one month after the final dose, day 21-60 after the final dose), were measured for HPV-16- and HPV-18-specific IgG antibodies. Due to the labor-consuming characteristics of PBNA, only serum samples at day 0 and month 7 were measured for neutralizing antibodies. Before antibody measurements, all the serum samples of month 6 and month 7 were renumbered to ensure the investigators, serum analyzers and sponsors remained blinded to the group assignments.

Detailed procedures have been described previously ( $\mathrm{Wu}$ et al., 2015; Zhao et al., 2014), though some methodological improvement was made for both assays. For PBNA, after culturing the diluted serum samples with pseudovirions and incubating with 293FT cell monolayers, the 96-well microtiter plates were scanned by an Enzyme-Linked Immunospot (ELISPOT) reader instead of reading by naked eye, and a $50 \%$ reduction or more in green fluorescent protein (GFP) expression compared with the negative control was defined as a positive sample. References traceable to WHO international standards for antibodies against HPV-16 (NIBSC code $05 / 134$ ) or HPV-18 (NIBSC code 10/140) were used for serum quantification. Neutralizing antibody serostatus cutoff values were 2.1 international units per $\mathrm{mL}\left(\mathrm{IU} \mathrm{mL}{ }^{-1}\right)$ for HPV-16 and 1.7 IU mL ${ }^{-1}$ for HPV-18. For ELISA, the same serum references were used for quantification, $\mathrm{IgG}$ serostatus cutoff values were $3.0 \mathrm{IU} \mathrm{mL}^{-1}$ for HPV 16 and $2.1 \mathrm{IU} \mathrm{mL}^{-1}$ for HPV-18. For seronegative samples, half of the cutoff value was artificially set as the antibody level.

\section{Statistical analyses}

The primary objective of this trial was to determine whether the immune responses (IgG antibodies to HPV-16 and HPV18) at month 7 (one month after the final dose) in girls 9-17 years receiving 3 doses of the candidate vaccine were noninferior to those in women aged 18-26 years receiving 3 doses of vaccine. Our secondary objectives included comparing the immune responses (IgG) in girls aged 9-14 years receiving 2 doses with those in women age 18-26 years receiving 3 doses and evaluating the vaccine safety in girls aged 9-17 years. For evaluating immune responses, both GMC levels and seroconversion rates to HPV-16 and HPV18 were assessed. An antibody concentration increase of 4 times or more was defined as seroconversion. Exploratory objectives included the abovementioned analysis for neutralizing antibodies and the noninferiority analysis of immune responses (for both IgG and neutralizing antibodies) at month 7 in girls aged 9-14 years receiving 2 doses compared with those in girls receiving 3 doses.

Sample size was estimated based on the primary objective with a 1-sided test at $\alpha=0.025$ and $90 \%$ study power of noninferiority among girls aged 9-17 years receiving 3 doses and women aged 18-26 years with a 2:1 allocation between the two groups. Estimates of assay variance and seroconversion rates were inferred from a Phase II clinical study (Wu et al., 2015). It was estimated that baseline seroprevalence would be $25 \%$ and $10 \%$ for HPV-16 and -18 , respectively and that there would be a $15 \%$ dropout rate. Girls aged 9-17 years receiving 3 doses were divided into three age groups equally according to age (9-11 years, 12-14 years and 15-17 years). The ratio of girls aged 9-14 years assigned to the 3-dose and the 2-dose group was $1: 1$. The noninferiority margins were set at 0.5 for the GMC ratio and $-5 \%$ for the seroconversion rate difference of $\mathrm{HPV}$ 16 and HPV-18 antibodies at month 7. Based on these parameters, 750 girls aged 9-17 years and 225 women aged 18-26 years would be enrolled.

The primary immunogenicity analysis was carried out in the per-protocol cohort, which included those who were antibody (the same antibody index and same HPV type)seronegative at entry, had received all the scheduled vaccine doses, and had no important protocol violation. All participants who received at least one dose were included in the intention-to-treat analysis, regardless of how many doses they received, whether they adhered to the protocol or their antibody status at baseline. All the participants who received at least one dose were included in the safety analysis.

Compliance and ethics M.G., B.-Z.L., Z.-J.L., and H.-R.P. report being either current or former employees of Xiamen Innovax. No other potential conflict of interest relevant to this article by the other authors was reported. All procedures performed in studies involving human participants were in accordance with the ethical standards of the institutional and/or national research committee and with the 1964 Helsinki declaration and its later amendments or comparable ethical standards.

Acknowledgements This work was supported by the National Natural Science Foundation of China (81673240, and U1705283), the Chinese National Major Scientific and Technological Special Project for "Significant New Drugs Development” (2018ZX09308010, 2012ZX09101316), the Fujian Provincial Major Scientific and Technological Project (2015YZ0002) and Xiamen Innovax.

\section{References}

Block, S.L., Nolan, T., Sattler, C., Barr, E., Giacoletti, K.E.D., Marchant, C. D., Castellsagué, X., Rusche, S.A., Lukac, S., Bryan, J.T., et al. (2006). Comparison of the immunogenicity and reactogenicity of a prophylactic quadrivalent human papillomavirus (types 6, 11, 16, and 18) L1 viruslike particle vaccine in male and female adolescents and young adult women. Pediatrics 118, 2135-2145.

Bruni, L., Albero, G., Serrano, B., Mena, M., Gómez, D., Muñoz, J., Bosch, F. X., de Sanjosé, S. (2019). ICO/IARC Information Centre on HPV and Cancer (HPV Information Centre). Human Papillomavirus and Related Diseases in the World. http://www.hpvcentre.net.

Chen, W., Zheng, R., Baade, P.D., Zhang, S., Zeng, H., Bray, F., Jemal, A., Yu, X.Q., and He, J. (2016). Cancer statistics in China, 2015. CA-A Cancer J Clin 66, 115-132.

de Martel, C., Plummer, M., Vignat, J., and Franceschi, S. (2017). Worldwide burden of cancer attributable to HPV by site, country and HPV type. Int J Cancer 141, 664-670.

Dobson, S.R.M., McNeil, S., Dionne, M., Dawar, M., Ogilvie, G., Krajden, 
M., Sauvageau, C., Scheifele, D.W., Kollmann, T.R., Halperin, S.A., et al. (2013). Immunogenicity of 2 doses of HPV vaccine in younger adolescents vs. 3 doses in young women: a randomized clinical trial. JAMA 309, 1793.

European Medicines Agency. Cervarix. Summary of Product Characteristics. http://www.ema.europa.eu/docs/en_GB/document_library/ EPAR_Product_Information/human/000721/WC500024632.pdf.

European Medicines Agency. Gardasil 9. Summary of Product Characteristics. http://www.ema.europa.eu/docs/en_GB/document_library/ EPAR_Product_Information/human/003852/WC500189111.pdf.

European Medicines Agency. Gardasil. Summary of Product Characteristics. http://www.ema.europa.eu/docs/en_GB/document_library/ EPAR_Product_Information/human/000703/WC500021142.pdf.

Future II Study Group. (2007). Quadrivalent vaccine against human papillomavirus to prevent high-grade cervical lesions. N Engl J Med, 356, 1915-1927.

Gu, Y., Wei, M., Wang, D., Li, Z., Xie, M., Pan, H., Wu, T., Zhang, J., Li, S., and Xia, N. (2017). Characterization of an Escherichia coli-derived human papillomavirus type 16 and 18 bivalent vaccine. Vaccine 35, 4637-4645.

Harper, D.M., Franco, E.L., Wheeler, C., Ferris, D.G., Jenkins, D., Schuind, A., Zahaf, T., Innis, B., Naud, P., De Carvalho, N.S., et al. (2004). Efficacy of a bivalent L1 virus-like particle vaccine in prevention of infection with human papillomavirus types 16 and 18 in young women: A randomised controlled trial. Lancet 364, 1757-1765.

Herrero, R., González, P., and Markowitz, L.E. (2015). Present status of human papillomavirus vaccine development and implementation. Lancet Oncol 16, e206-e216.

Hu, Y.M., Huang, S.J., Chu, K., Wu, T., Wang, Z.Z., Yang, C.L., Cai, J.P., Jiang, H.M., Wang, Y.J., Guo, M., et al. (2014). Safety of an Escherichia coli-expressed bivalent human papillomavirus (types 16 and 18) L1 virus-like particle vaccine: An open-label phase I clinical trial.. Human Vaccines Immun 10, 469-475.

Huang, X., Wang, X., Zhang, J., Xia, N., and Zhao, Q. (2017). Escherichia coli-derived virus-like particles in vaccine development. NPJ Vaccines 2, 3.

Iversen, O.E., Miranda, M.J., Ulied, A., Soerdal, T., Lazarus, E., Chokephaibulkit, K., Block, S.L., Skrivanek, A., Nur Azurah, A.G., Fong, S.M., et al. (2016). Immunogenicity of the 9-valent HPV vaccine using 2-dose regimens in girls and boys vs. a 3-dose regimen in women. JAMA 316, 2411-2421.

Jingyee Kou, T. M., and A. Dale Horne. (2009). Statistical review and evaluation. http://www.fda.gov/downloads/BiologicsBloodVaccines/ Vaccines/ApprovedProducts/UCM206200.pdf.

Joura, E.A., Giuliano, A.R., Iversen, O.E., Bouchard, C., Mao, C., Mehlsen, J., Moreira Jr., E.D., Ngan, Y., Petersen, L.K., Lazcano-Ponce, E., et al. (2015). A 9-valent HPV vaccine against infection and intraepithelial neoplasia in women. N Engl J Med 372, 711-723.

Joura, E.A., Kjaer, S.K., Wheeler, C.M., Sigurdsson, K., Iversen, O.E., Hernandez-Avila, M., Perez, G., Brown, D.R., Koutsky, L.A., Tay, E.H., et al. (2008). HPV antibody levels and clinical efficacy following administration of a prophylactic quadrivalent HPV vaccine. Vaccine 26 , 6844-6851.

Kjaer, S.K., Nygård, M., Dillner, J., Brooke Marshall, J., Radley, D., Li, M., Munk, C., Hansen, B.T., Sigurdardottir, L.G., Hortlund, M., et al. (2018). A 12-year follow-up on the long-term effectiveness of the quadrivalent human papillomavirus vaccine in 4 nordic countries. Clin Infect Dis 66, 339-345.
Liu, W., Wei, F., Tang, J., Yang, S., Gao, Y., Wang, T., Jiang, Y., Li, M., Hong, Y., Chu, K., et al. (2016). Detection of neutralizing antibodies and DNA of human papillomavirus 16, 18 in women aged 18-45 years in Funing, Jiangsu Province. Chin J Epidemiol, 37, 406-409.

Mariani, L., Cristoforoni, P., Perino, A., Stigliano, C. M. and Preti, M. (2016). Nonavalent HPV vaccine (HPV-9): Analysis of pre-registration data. Minerva Ginecol, 68, 620-621.

Olsson, S.E., Villa, L.L., Costa, R.L.R., Petta, C.A., Andrade, R.P., Malm, C., Iversen, O.E., Høye, J., Steinwall, M., Riis-Johannessen, G., et al. (2007). Induction of immune memory following administration of a prophylactic quadrivalent human papillomavirus (HPV) types 6/11/16/ 18 L1 virus-like particle (VLP) vaccine. Vaccine 25, 4931-4939.

Pedersen, C., Petaja, T., Strauss, G., Rumke, H.C., Poder, A., Richardus, J. H., Spiessens, B., Descamps, D., Hardt, K., Lehtinen, M., et al. (2007). Immunization of early adolescent females with human papillomavirus type 16 and $18 \mathrm{~L} 1$ virus-like particle vaccine containing AS04 adjuvant. J Adolescent Health 40, 564-571.

Qiao, Y.L., Wu, T., Li, R.C., Hu, Y.M., Wei, L.H., Li, C.G., Chen, W., Huang, S.J., Zhao, F.H., Li, M.Q., et al. (2019). Efficacy, safety, and immunogenicity of an Escherichia coli-produced bivalent human papillomavirus vaccine: An interim analysis of a randomized clinical trial. J Natl Cancer Inst. (Epub ahead of print), https://doi.org/10.1093/jnci/ djz074.

Romanowski, B., Schwarz, T.F., Ferguson, L.M., Peters, K., Dionne, M., Schulze, K., Ramjattan, B., Hillemanns, P., Catteau, G., Dobbelaere, K., et al. (2011). Immunogenicity and safety of the HPV-16/18 AS04adjuvanted vaccine administered as a 2-dose schedule compared to the licensed 3-dose schedule: Results from a randomized study.. Human Vaccines 7, 1374-1386.

Stanley, M., Lowy, D.R., and Frazer, I. (2006). Chapter 12: Prophylactic HPV vaccines: Underlying mechanisms. Vaccine 24, S106-S113.

Van Damme, P., Olsson, S.E., Block, S., Castellsague, X., Gray, G.E., Herrera, T., Huang, L.M., Kim, D.S., Pitisuttithum, P., Chen, J., et al. (2015). Immunogenicity and safety of a 9-valent HPV vaccine. Pediatrics 136, e28-e39.

World Health Organization. (2014). Human papillomavirus vaccines: WHO position paper. Wkly Epidemiol Rec, 89, 465-491.

World Health Organization. (2017). Human papillomavirus vaccines: WHO position paper. Wkly Epidemiol Rec, 92, 241-268.

World Health Organization. (2018). WHO Director-General calls for all countries to take action to help end the suffering caused by cervical cancer. http://www.who.int/reproductivehealth/call-to-action-elimination-cervical-cancer/en/.

Wu, T., Hu, Y.M., Li, J., Chu, K., Huang, S.J., Zhao, H., Wang, Z.Z., Yang, C.L., Jiang, H.M., Wang, Y.J., et al. (2015). Immunogenicity and safety of an E. coli-produced bivalent human papillomavirus (type 16 and 18) vaccine: A randomized controlled phase 2 clinical trial. Vaccine 33, 3940-3946.

Zhao, F.H., Tiggelaar, S.M., Hu, S.Y., Xu, L.N., Hong, Y., Niyazi, M., Gao, X.H., Ju, L.R., Zhang, L.Q., Feng, X.X., et al. (2012). A multi-center survey of age of sexual debut and sexual behavior in Chinese women: Suggestions for optimal age of human papillomavirus vaccination in China. Cancer Epidemiol 36, 384-390.

Zhao, H., Lin, Z.J., Huang, S.J., Li, J., Liu, X.H., Guo, M., Zhang, J., Xia, N.S., Pan, H.R., Wu, T., et al. (2014). Correlation between ELISA and pseudovirion-based neutralisation assay for detecting antibodies against human papillomavirus acquired by natural infection or by vaccination. Human Vaccines Immun 10, 740-746. 


\section{SUPPORTING INFORMATION}

Figure S1 Reverse cumulative distribution curves of IgG and neutralizing antibodies at month 7 (PPS cohort).

Table S1 Noninferiority analysis of seroconversion rate in the ITT cohort

Table S2 Noninferiority analysis of geometric mean concentrations (GMCs) in the PPS cohort

Table S3 Noninferiority analysis of geometric mean concentrations (GMCs) in the ITT cohort

Table S4 Noninferiority analysis of geometric mean concentrations (GMCs) in girls who received 2 doses vs 3 doses (per-protocol cohort)

Table S5 Adverse events reported within 30 days after each dose

Table S6 Listing of serious adverse events (SAEs) reported during the study (from day 0 to month 7)

Table S7 Study inclusion and exclusion criteria

The supporting information is available online at http://life.scichina.com and https://link.springer.com. The supporting materials are published as submitted, without typesetting or editing. The responsibility for scientific accuracy and content remains entirely with the authors. 